Gut and Liver, Vol. 12, No. 1, January 2018, pp. 58-66

\title{
Helicobacter pylori Is Associated with miR-133a Expression through Promoter Methylation in Gastric Carcinogenesis
}

\author{
Joo Hyun Lim ${ }^{1,2}$, Sang Gyun Kim², Ji Min Choi ${ }^{1}$, Hyo-Joon Yang ${ }^{3}$, Joo Sung Kim ${ }^{1,2}$, and Hyun Chae Jung ${ }^{2}$ \\ ${ }^{1}$ Department of Internal Medicine and Healthcare Research Institute, Healthcare System Gangnam Center, Seoul National University \\ Hospital, ${ }^{2}$ Department of Internal Medicine and Liver Research Institute, Seoul National University College of Medicine, and ${ }^{3}$ Division of \\ Gastroenterology, Department of Internal Medicine and Gastrointestinal Cancer Center, Kangbuk Samsung Hospital, Sungkyunkwan University \\ School of Medicine, Seoul, Korea
}

Background/Aims: To investigate whether Helicobacter pylori eradication can reverse epigenetic silencing of microRNAs (miRNAs) which are associated with $H$. pylori-induced gastric carcinogenesis. Methods: We examined expression and promoter methylation of miR-34b/c, miR-133a, let-7a, and let-7i in gastric cancer cell line, before/after demethylation. Among them, epigenetically controlled miRNAs were identified. Their expression and promoter methylation was examined in human tissues of $H$. pylori-positive gastric cancer $(\mathrm{T}), H$. pyloripositive gastritis $(H)$, and $H$. pylori-negative controls $(C)$. We also compared changes of miRNA expression and promoter methylation in $\mathrm{H}$. pylori-positive patients who were endoscopically treated for early gastric cancer, between baseline and 1 year later according to eradication status. Results: In gastric cancer cell line, miR-34b/c and miR-133a showed epigenetic silencing. In human tissues, miR-34b/c and miR133a showed serial increase of promoter methylation in order of $\mathrm{C}, \mathrm{H}$, and $\mathrm{T}$ (all, $\mathrm{p}<0.01$ ), and the miR-133a expression showed serial decrease ( $C$ vs $H, p=0.02 ; H$ vs $T, p=0.01$; $C$ vs $\mathrm{T}, \mathrm{p}<0.01$ ) while miR-34b and miR-34c expressions did not. $H$. pylori eradication induced decrease of methylation $(p<0.01)$ and increase of miR-133a expression ( $p=0.03)$, compared with noneradication group. Conclusions: This result suggests H. pylori eradication could reverse methylation-silencing of miR-133a which is involved in $\mathrm{H}$. pylori-induced gastric carcinogenesis. (Gut Liver 2018;12:58-66)

Key Words: Helicobacter pylori; Methylation; MicroRNAs; Stomach neoplasms

\section{INTRODUCTION}

MicroRNAs (miRNAs) are short noncoding RNAs consisting of about 22 nucleotides, which are known to function in posttranscriptional modulation in the way of epigenetic changes such as translational repression or messenger RNA cleavage. ${ }^{1}$ Recently, many studies have revealed that various miRNAs are involved in human carcinogenesis. For example, miR-21 has been shown to be associated with adenoma-carcinoma sequence of colon cancer. ${ }^{2}$ Also, $m i R-21$ and $m i R-27$ a were reported to be related to gastric carcinogenesis. ${ }^{3,4}$ DNA methylation is another well-known epigenetic phenomenon which induces transcriptional regulation, and it is already established that a great deal of tumor suppressor genes are controlled by promoter methylation. In the meanwhile, miRNA expression is also influenced by epigenetic alterations. ${ }^{5}$ Several studies have reported that expression of certain miRNAs are epigenetically regulated by promoter $\mathrm{CpG}$ island methylation of the miRNA genes in gastric cancer. $^{6-8}$

$\mathrm{miR}-34 \mathrm{~b} / \mathrm{c}$ was previously found to be silenced by promoter $\mathrm{CpG}$ island hypermethylation in colorectal cancer ${ }^{9}$ and gastric cancer. ${ }^{7}$ Also, a recent study has shown that aberrant methylation of $\mathrm{miR}-34 \mathrm{~b} / \mathrm{c}$ is associated with metachronous gastric cancer. ${ }^{10}$ This study also showed that the promoter methylation of $m i R-34 b / c$ is related with Helicobacter pylori infection. Let-7 family is an essential developmental regulator, which is one of the first known miRNAs. ${ }^{11}$ Let-7 genes are thought to be related with tumor suppression, as the expression of which is considerably low in many cancers. ${ }^{12}$ In a previous study, let-7 expression was shown to be downregulated by cytotoxin-associated gene $\mathrm{A}$ of $H$. pylori by histone modification and DNA methyla-

\footnotetext{
Correspondence to: Sang Gyun Kim

Division of Gastroenterology, Department of Internal Medicine and Liver Research Institute, Seoul National University College of Medicine, 101 Daehak-ro, Jongno-gu, Seoul 03080, Korea

Tel: +82-2-740-8112, Fax: +82-2-743-6701, E-mail: harley1333@hanmail.net

Received on June 16, 2017. Revised on August 4, 2017. Accepted on September 14, 2017. Published online September 28,2017

pISSN 1976-2283 eISSN 2005-1212 https://doi.org/10.5009/gnl17263

@ This is an Open Access article distributed under the terms of the Creative Commons Attribution Non-Commercial License (http://creativecommons.org/licenses/by-nc/4.0) which permits unrestricted non-commercial use, distribution, and reproduction in any medium, provided the original work is properly cited.
} 
tion of its promoter. ${ }^{8}$ miR-133 is another miRNA which was reported to be associated with $H$. pylori infection. A previous study has revealed that miR-133 was downregulated by longterm infection with $H$. pylori in mice. ${ }^{13}$ In recent studies, miR133 was demonstrated to play tumor suppressive role in gastric carcinogenesis. ${ }^{14-17}$ However, whether H. pylori eradication therapy could reverse the modulation of these miRNAs has not been clarified yet. Therefore, we aimed to clarify whether the miRNAs which are associated with gastric carcinogenesis could be reversed by $H$. pylori eradication therapy.

\section{MATERIALS AND METHODS}

\section{1. miRNA and promoter $\mathrm{CpG}$ island selection}

Based on literature review, $m i R-34 \mathrm{~b} / \mathrm{c}$, let-7, and $m i R-133 \mathrm{a}$ were selected as miRNAs which are possibly associated with $H$. pylori-induced gastric carcinogenesis. miR-34b and miR-34c are a pair of miRNAs, whose genes are closely located within 418 bp distance in 11q23.1, and they are encoded by common promoter sequence. Therefore we measured expression levels of miR-34b and miR-34c each, and promoter methylation levels of $\mathrm{miR}-34 \mathrm{~b} / \mathrm{c}$. Among let-7 series, let-7a-3 located in 22q13.31 and let-7i in 12q14.1 were selected, as they were the only miRNAs whose promoters contain CpG islands. miR-133a is a miRNA encoded by two genes, miR-133a-1 and miR-133a-2. Among them, we measured promoter methylation of $m i R$ 133a-2 gene for the same reason as in let-7.

\section{Cell line and demethylation}

Gastric cancer cell lines AGS and KATO III (Table 1) were obtained from Korean Cell Line Bank and cultured in RPMI 1640 with L-glutamine ( $300 \mathrm{mg} / \mathrm{L}$ ), $25 \mathrm{mM}$ HEPES and 25 $\mathrm{mM} \mathrm{NaHCO}, 90 \%$; heat inactivated fetal bovine serum, 10\%. On day 0 , cells were seeded, and the media was added with 2 $\mu \mathrm{M}$ 5-Aza-2'-deoxycytidine (Sigma-Aldrich and Merck KGaA, Darmstadt, Germany), the demethylating agent, on the next day. Cells were treated with 5-Aza-2'-deoxycytidine for 72 hours, while daily replacing the demethylating agent and medium. On day 4 , cells were harvested.

\section{Tissue samples}

Gastric mucosal tissue samples were obtained from cancerous mucosa of 24 patients with gastric cancer ( $T$, tumor group), antral mucosa of 24 patients with $H$. pylori-positive gastritis $(H$, $H$. pylori-gastritis group), and antral mucosa of $24 \mathrm{H}$. pylorinegative healthy volunteers ( $C$, control group). All the T, $\mathrm{H}$, and C groups were enrolled between October 2013 and September 2014. H. pylori status was considered positive when either the rapid urease test or histologic examination showed a positive result. To assess the effect of $H$. pylori eradication, noncancerous mucosal tissues of $24 \mathrm{H}$. pylori-positive early gastric cancer

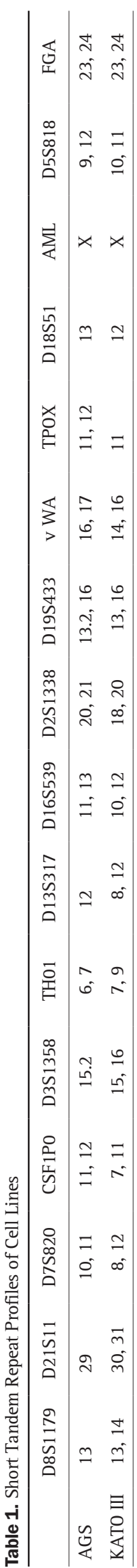


patients who were endoscopically treated were also obtained between January 2012 and December 2012. Then they were randomly assigned to $H$. pylori eradication group (E) and noneradication group (NE). E group received $20 \mathrm{mg}$ of omeprazole, $1 \mathrm{~g}$ of amoxicillin, and $500 \mathrm{mg}$ of clarithromycin, twice a day for 7 days. Twelve months later, gastric antral mucosal tissues were taken from the E and NE groups during the follow-up endoscopy and rapid urease tests were performed as well. Final $H$. pylori status was also evaluated with rapid urease test and histologic examination. When either of those studies showed positive, it was considered as positive. From all tissue samples, degrees of atrophic gastritis and intestinal metaplasia were measured by the updated Sydney system. ${ }^{18}$ And then the remaining tissue samples were restored at $-80^{\circ} \mathrm{C}$. Also, degrees of neutrophilic infiltration and monocytic infiltration were measured. All the patients enrolled in this study were $\geq 18$ years old, had no other cancer, and were not taking nonsteroidal anti-inflammatory drugs nor proton pump inhibitors. This study was approved by Seoul National University Hospital Institutional Review Board (IRB number: H-1309-017-518) and complied with the Declaration of Helsinki. From all the participants, informed consent was obtained before tissue retrieval.

\section{Real-time reverse transcription polymerase chain reac- tion of miRNA}

The miRNAs were isolated from tissues and cells stored at $-80^{\circ} \mathrm{C}$ using mirVana miRNA Isolation Kit (Ambion, Austin, TX, USA). Reverse transcription of the miRNAs into the singlestranded cDNAs were performed using TaqMan MicroRNA Reverse Transcription Kit (Applied Biosystems, Darmstadt, Germany). Quantitative polymerase chain reaction (PCR) was conducted using TaqMan Universal Master Mix II (Applied Biosystems). The relative expression levels of the miRNAs were calculated using the relative quantification $\left(2^{-\Delta \Delta \mathrm{ct}}\right)$ method $^{19}$ with duplicate measurements for tissue samples. However, cell line experiments were performed in triplicate to minimize potential errors induced by misidentification or contamination.

\section{DNA isolation and bisulfite modification}

DNA was isolated from the tissues and cells using phenolchloroform extraction method. Bisulfite modification which converts unmethylated cytosine into uracil was performed using EZ DNA Methylation Kit (Zymo Research, Orange, CA, USA) (Table 2).

\section{Methylation analysis}

For methylation analysis, we used MethyLight technique based on quantitative PCR method ${ }^{20-22}$ with duplicate measurements for tissue samples and triplicate for cell lines. Pairs of primers and probes to bind bisulfite-converted DNA were designed using the software, Beacon Designer (Premier Biosoft, Palo Alto, CA, USA). To report the levels of DNA methylation, percentage of methylated reference (PMR) was calculated as follows: $\mathrm{PMR}=100 \times(\text { methylated reaction/ALU })_{\text {sample }} /($ methylated reaction/ALU) $)_{\mathrm{M} . S s s}$.

\section{Statistical analysis}

To analyze continuous variables with normal distribution, ttest or analysis of variance was applied between two or more than two groups, respectively. To analyze continuous variables which are not normally distributed, Wilcoxon rank-sum test and Wilcoxon signed-rank test were applied for independent and paired samples, respectively. For nominal variables, chi-square test or Fisher exact test was applied. When $>20 \%$ of expected frequencies were $\leq 5$, Fisher exact test was used. Otherwise, chisquare test was used. For repeated measures, generalized linear mixed model was applied. p-values less than 0.05 were considered significant. $\mathrm{p}$-values were presented without multiple test-

Table 2. Primers and Probes Used in MethyLight Assay

\begin{tabular}{|c|c|c|c|c|}
\hline Gene & Primer/probe & Sequence $\left(5^{\prime} \rightarrow 3^{\prime}\right)$ & Length, bp & $\mathrm{T}_{\mathrm{m}},{ }^{\circ} \mathrm{C}$ \\
\hline \multirow[t]{3}{*}{$\mathrm{miR}-34 \mathrm{~b} / \mathrm{c}$} & Forward primer & TTCGCGGGGTTTTAAGGACG & 20 & 59.0 \\
\hline & Reverse primer & CAAАСССТАAАACTAАСТСТСТСGAC & 26 & 58.9 \\
\hline & Probe & CCGCCGCTCTAAACGACCGAATAACTAT & 28 & 66.3 \\
\hline \multirow[t]{3}{*}{ let-7a-3 } & Forward primer & GGGAGTTGAGAGTTAGTATGTCGTT & 25 & 59.2 \\
\hline & Reverse primer & CGCCTCAACСТCCСАAАATACT & 22 & 59.1 \\
\hline & Probe & AACATAAACCACTACGCCCGACCTACTTCC & 30 & 67.7 \\
\hline \multirow[t]{3}{*}{ let-7i } & Forward primer & TTTCGAAGGGTGTTGGGGAAC & 21 & 59.0 \\
\hline & Reverse primer & CCGACGAACATCCCGCAAAA & 20 & 59.6 \\
\hline & Probe & TACCGCCGACTCCGCCAAACAACAA & 25 & 68.1 \\
\hline \multirow[t]{3}{*}{$m i R-133 a-2$} & Forward primer & GCTCGATATCTATTCACAACTCACG & 25 & 58.8 \\
\hline & Reverse primer & CGGGGAGGTTATTGCGGTTT & 20 & 58.7 \\
\hline & Probe & CACCACCGTAACGACTACAACGCCAA & 26 & 66.6 \\
\hline
\end{tabular}

$\mathrm{T}_{\mathrm{m}}$, melting temperature. 
ing. All statistical analyses were performed using SPSS version 21.0 (IBM Corp., Armonk, NY, USA).

\section{RESULTS}

\section{Identification of miRNAs silenced by promoter methyla- tion in gastric cancer cell line}

In gastric cancer cell lines, AGS and KATO III, the levels of expression of miRNAs and promoter DNA methylation were measured before and after demethylation with 5-Aza-2'deoxycytidine. After demethylation, the promoter methylation levels of $m i R-34 b / c$ and $m i R-133 a-2$ were decreased by about 30\% in AGS and about 50\% in KATO III, and the levels of expression of $m i R-34 b, m i R-34 c$, and $m i R-133 a$ were increased by about 10-fold in AGS and more than 3-fold in KATO III. On the other hand, the promoter methylation levels of let-7i were decreased by less than 10\% in AGS and 60\% in KATO III, and its expression levels were increased by only about 2-fold in AGS and KATO III after demethylation. The promoter methylation levels of let-7a were decreased by about 30\% in AGS and $50 \%$ in KATO III, and the expression levels of which were only increased by 70\% in AGS and 40\% in KATO III after demethylation (Fig. 1).

A

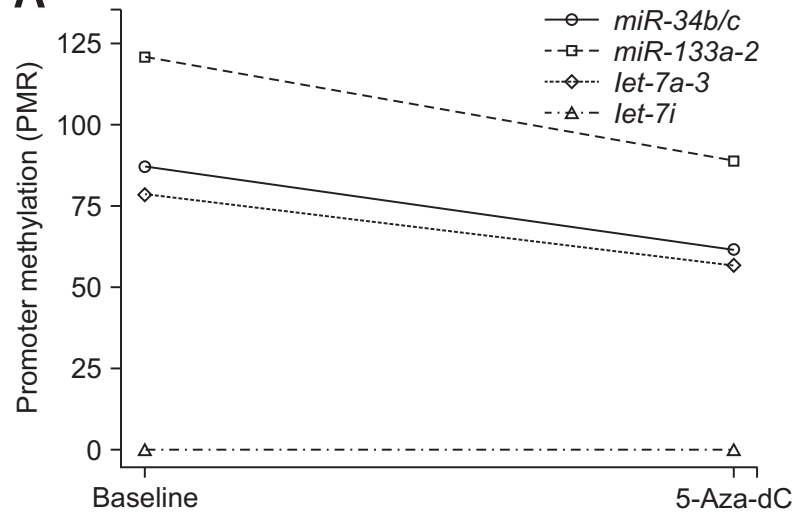

C

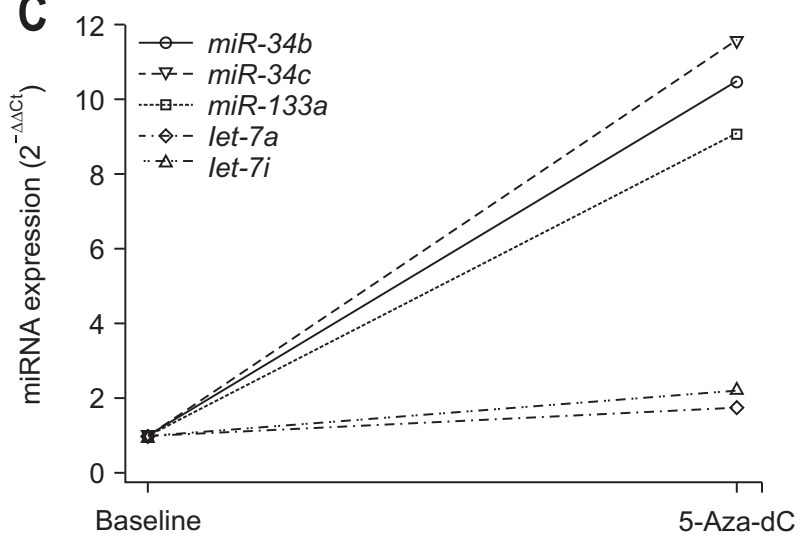

\section{Clinicopathological characteristics of enrolled patients}

Overall 96 patients were enrolled in this study. Their clinicopathological characteristics are presented in Table 3. Mean age was the highest in $\mathrm{T}$, then $\mathrm{H}$ and $\mathrm{C}$ group, respectively $(\mathrm{p}<0.01)$. Also, the degrees of atrophic gastritis, intestinal metaplasia, neutrophilic infiltration, and monocytic infiltration showed the same pattern (all, $\mathrm{p}<0.01$ ). However, there was no significant difference in gender proportion among the three groups $(\mathrm{p}=0.25)$. Also, there was no significant difference in clinicopathological characteristics between the eradication and noneradication group, at the time of enrollment.

\section{Promoter methylation and expression levels of miRNAs according to disease status}

In human gastric mucosal tissues, we measured promoter methylation levels of $m i R-34 b / c$ and $m i R-133 a-2$, which were found to be epigenetically silenced by promoter methylation in above mentioned gastric cancer cell line experiment. In promoters of both miRNAs, the methylation levels were the highest in $\mathrm{T}$, then $\mathrm{H}$ and $\mathrm{C}$ group, respectively, and the difference between each pair of groups was statistically significant (all, $\mathrm{p}<0.01$ ) (Fig. 2). We then examined the expression levels of $m i R-34 b, 34 c$,
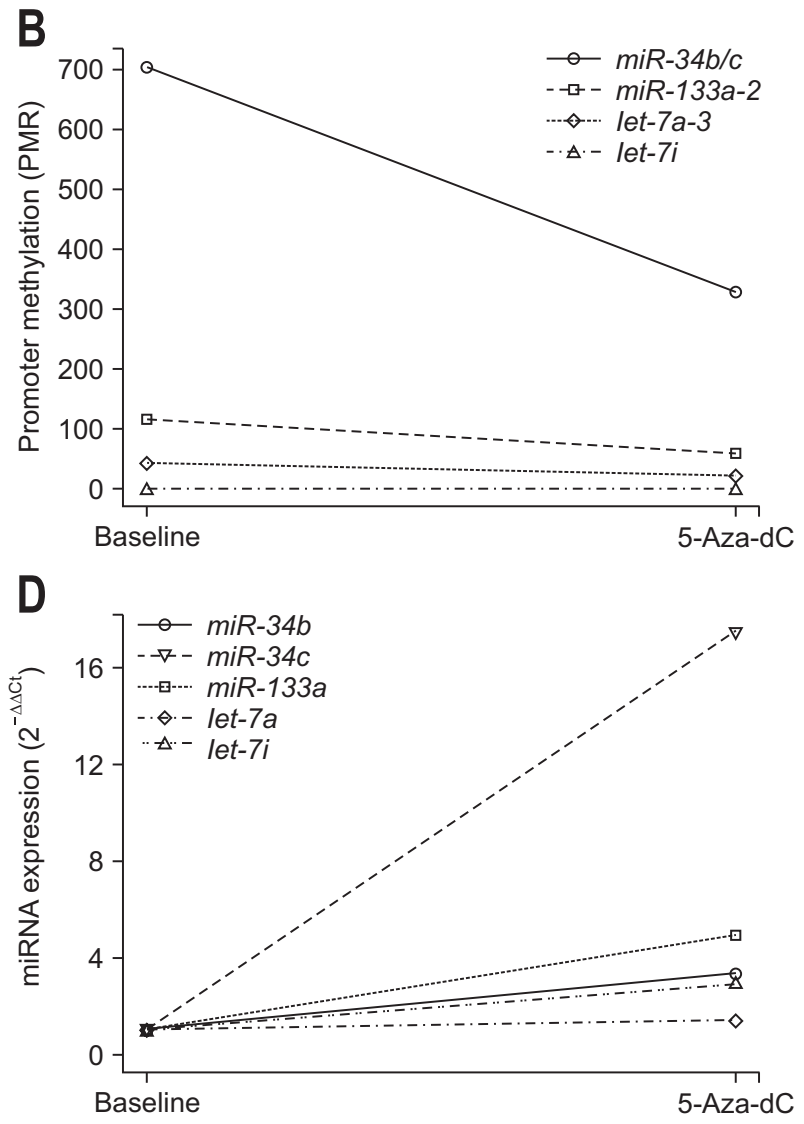

Fig. 1. Changes of promoter methylation (A, AGS; B, KATO III) and miRNA expression levels (C, AGS; D, KATO III) before and 72 hours after demethylation with 5-Aza-2'-deoxycytidine in gastric cancer cell lines AGS and KATO III. miRNA, microRNA; PMR, percentage of methylated reference; 5-Aza-dC, 5-Aza-2'-deoxycytidine. 
Table 3. Baseline Clinicopathological Characteristics

\begin{tabular}{|c|c|c|c|c|c|c|c|}
\hline Characteristic & $\begin{array}{l}\text { Tumor } \\
(n=24)\end{array}$ & $\begin{array}{l}H . \text { pylori-gastritis } \\
(\mathrm{n}=24)\end{array}$ & $\begin{array}{l}\text { Control } \\
(n=24)\end{array}$ & p-value & $\begin{array}{l}\text { Near tumor } \\
\text { eradication } \\
\qquad(n=12)\end{array}$ & $\begin{array}{c}\text { Near tumor } \\
\text { noneradication } \\
(n=12)\end{array}$ & p-value ${ }^{\dagger}$ \\
\hline Age, yr & $63.5(53.5-69.8)$ & $59.0(42.3-64.0)$ & $42.5(33.3-52.0)$ & $<0.01$ & $53.5(50.5-60.8)$ & $57.0(49.0-67.3)$ & 0.50 \\
\hline \multicolumn{8}{|l|}{ Sex } \\
\hline Male & $14(58.3)$ & $9(37.5)$ & $9(37.5)$ & 0.25 & $11(91.7)$ & $8(66.7)$ & 0.32 \\
\hline Female & $10(41.7)$ & $15(62.5)$ & $15(62.5)$ & & $1(8.3)$ & $4(33.3)$ & \\
\hline \multicolumn{8}{|l|}{ Atrophic gastritis $^{\ddagger}$} \\
\hline Absent & $5(29.4)$ & $9(39.1)$ & $23(95.8)$ & $<0.01$ & $2(16.7)$ & $4(33.3)$ & NA \\
\hline Mild & 3 (17.6) & $10(33.3)$ & $1(4.2)$ & & $5(41.7)$ & $3(25.0)$ & \\
\hline Moderate & $7(41.2)$ & $4(17.4)$ & 0 & & $5(41.7)$ & $1(8.3)$ & \\
\hline Marked & $2(11.8)$ & 0 & 0 & & 0 & $1(8.3)$ & \\
\hline \multicolumn{8}{|l|}{ Intestinal metaplasia } \\
\hline Absent & $4(16.7)$ & $10(41.7)$ & $24(100)$ & $<0.01$ & $2(16.7)$ & $1(8.3)$ & 0.83 \\
\hline Mild & $7(29.2)$ & $9(37.5)$ & 0 & & $4(33.3)$ & $5(41.7)$ & \\
\hline Moderate & $7(29.2)$ & $4(16.7)$ & 0 & & $4(33.3)$ & $4(33.3)$ & \\
\hline Marked & $6(25.0)$ & $1(4.2)$ & 0 & & $2(16.7)$ & $2(16.7)$ & \\
\hline \multicolumn{8}{|c|}{ Neutrophilic infiltration } \\
\hline Absent & $1(4.2)$ & 0 & $21(87.5)$ & $<0.01$ & 0 & 0 & 0.65 \\
\hline Mild & 0 & 0 & $3(12.5)$ & & $1(8.3)$ & 0 & \\
\hline Moderate & $16(66.7)$ & $18(75.0)$ & 0 & & $9(75.0)$ & $10(83.3)$ & \\
\hline Marked & $7(29.2)$ & $6(25.0)$ & 0 & & $2(16.7)$ & $2(16.7)$ & \\
\hline \multicolumn{8}{|l|}{ Monocytic infiltration } \\
\hline Absent & 0 & 0 & 0 & $<0.01$ & 0 & 0 & 1.00 \\
\hline Mild & $2(8.3)$ & 0 & $22(91.7)$ & & 0 & 0 & \\
\hline Moderate & $16(66.7)$ & $15(62.5)$ & $2(8.3)$ & & $10(83.3)$ & $9(75.0)$ & \\
\hline Marked & $6(25.0)$ & $9(37.5)$ & 0 & & $2(16.7)$ & $3(25.0)$ & \\
\hline
\end{tabular}

Data are presented as median (interquartile range) or number (\%).

H. pylori, Helicobacter pylori; NA, not available.

${ }^{*}$ Comparison was performed among tumor, $H$. pylori-gastritis, and control group; ${ }^{\dagger}$ Comparison was performed between near tumor eradication and noneradication group. Results are showing their initial status, not the status after treatment; ${ }^{\ddagger}$ Because of missing data, the sum of each does not match the total.

A

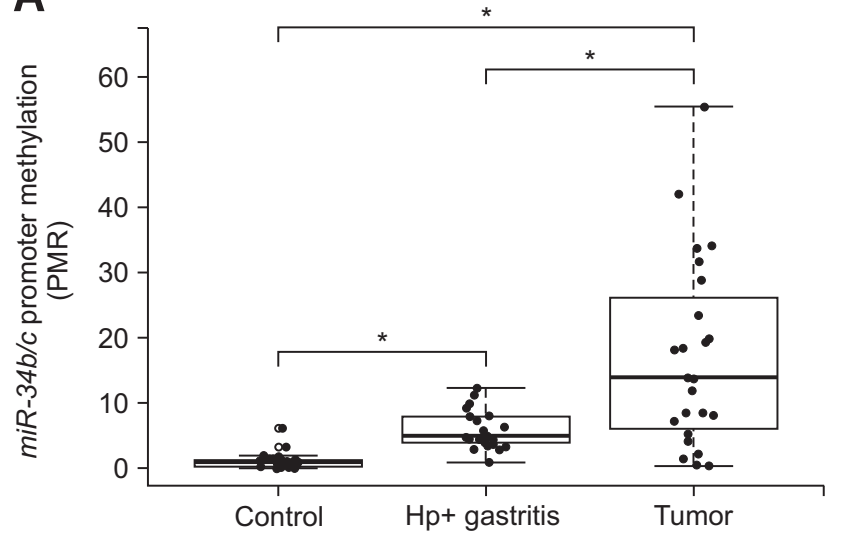

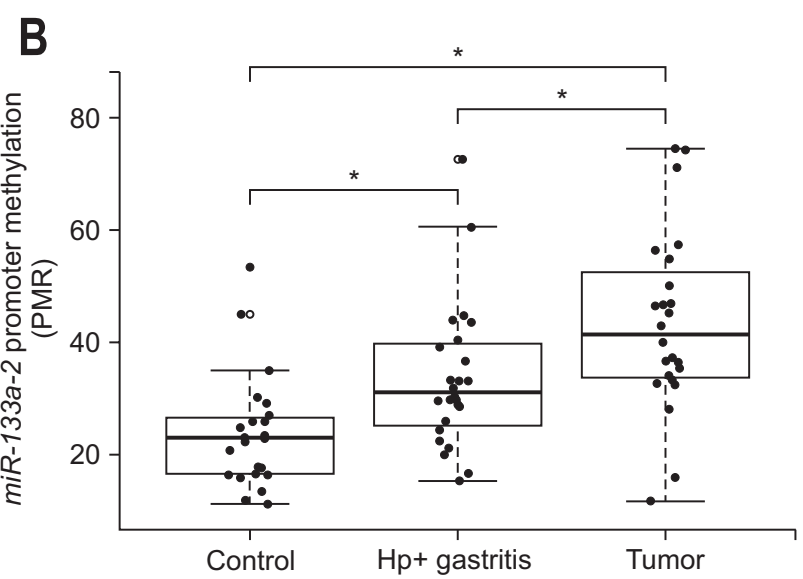

Fig. 2. Promoter methylation levels, reported as percentage of methylated reference (PMR), of miR-34b/c (A) and miR-133a-2 (B) in gastric mucosal tissues of Helicobacter pylori negative control, $H$. pylori positive gastritis, and $H$. pylori positive gastric cancer. Hp+, H. pylori positive. ${ }^{*} \mathrm{p}<0.01$. 

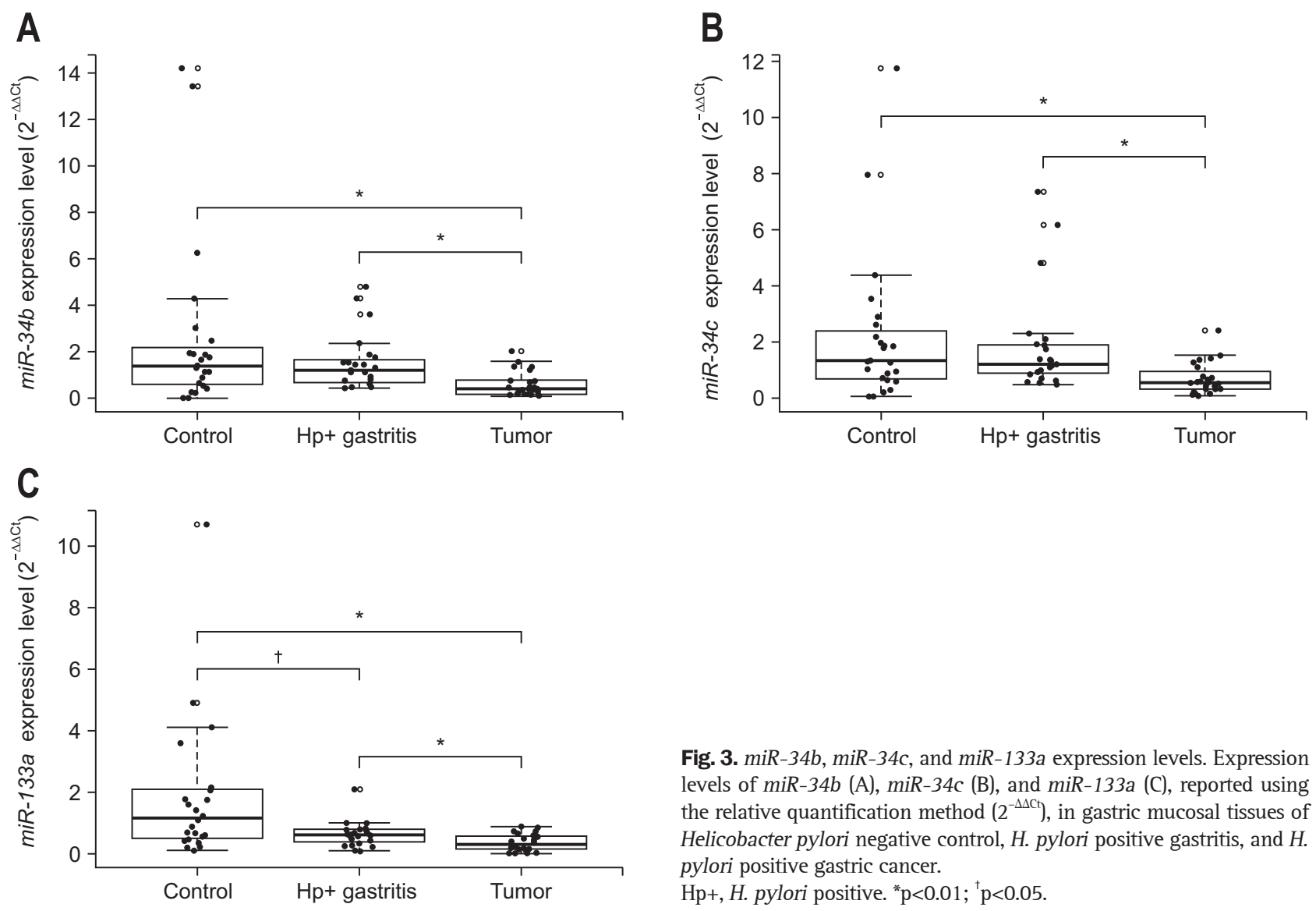

Fig. 3. $m i R-34 b$, $m i R-34 c$, and $m i R-133 a$ expression levels. Expression levels of miR-34b (A), miR-34c (B), and miR-133a (C), reported using the relative quantification method $\left(2^{-\Delta \Delta C}\right)$, in gastric mucosal tissues of Helicobacter pylori negative control, $H$. pylori positive gastritis, and $H$. pylori positive gastric cancer.

Hp+, H. pylori positive. ${ }^{*} \mathrm{p}<0.01 ;{ }^{\dagger} \mathrm{p}<0.05$.

and 133a. Among them, only miR-133a showed serial decrease of expression level in the order of $\mathrm{C}, \mathrm{H}$, and then $\mathrm{T}$ group. The difference between every two groups was also significant $(p=0.02$ in $\mathrm{C}$ vs $\mathrm{H}, \mathrm{p}=0.01$ in $\mathrm{H}$ vs $\mathrm{T}$, and $\mathrm{p}<0.01$ in $\mathrm{C}$ vs $\mathrm{T}$ ) (Fig. $3 \mathrm{C}$ ). In the meanwhile, although miR-34b and 34c showed lower levels of expression in $\mathrm{T}$ compared with $\mathrm{C}$ and $\mathrm{H}$, respectively (both miR-34b and 34c; $\mathrm{p}<0.01$ in $\mathrm{T}$ vs $\mathrm{C}, \mathrm{p}<0.01$ in $\mathrm{T}$ vs $\mathrm{H}$ ), they showed no significant difference between $\mathrm{C}$ and $\mathrm{H}$ group ( $m i R$ 34b, $\mathrm{p}=0.63$; miR-34c, $\mathrm{p}=0.90$ ) (Fig. 3A and B).

\section{Promoter methylation and expression level of $m i R-133 a$ under age adjustment}

As the age showed significant difference among the three groups, we further performed adjustment analysis. We performed analysis of covariance for age adjustment in promoter methylation and expression levels of miR-133a, which was the only miRNA showing serial increase of methylation and decrease of miRNA expression in the progress of $H$. pylori-related gastric cancer development. In this analysis, the promoter methylation was found to be significantly different among C, $\mathrm{H}$, and $\mathrm{T}$ group, even after the age adjustment $(\mathrm{p}<0.01)$. Besides, age was not a predictor for the promoter methylation $(\mathrm{p}=0.70)$. Also, the miR-133a expression level showed significant difference among the three groups under the age adjustment ( $p=0.01$ ),

Table 4. ANCOVA Analysis for Promoter Methylation and miR Expression Levels According to Groups under Age Adjustment

\begin{tabular}{lcccccc}
\hline & \multicolumn{2}{c}{ Promoter methylation level } & & \multicolumn{2}{c}{ miR expression level } \\
\cline { 2 - 3 } \cline { 5 - 6 } & $\mathrm{F}$ & $\mathrm{p}$-value & & $\mathrm{F}$ & $\mathrm{p}$-value \\
\hline Age & 0.15 & 0.70 & & 0.14 & 0.71 \\
Group & 7.72 & $<0.01$ & & 5.14 & 0.01 \\
\hline
\end{tabular}

ANCOVA, analysis of covariance; miR, microRNA.

and age was not associated with the miR-133a expression level $(\mathrm{p}=0.71)$ (Table 4).

\section{Changes of promoter methylation and expression of miR-133a according to $H$. pylori eradication status}

Among the E and NE groups which all had current $H$. pylori infection, half eradicated $H$. pylori (E group) and half did not (NE group). In E group, the eradication was successful in every patient. One year later, the promoter methylation level tended to decrease in the E group, while it increased in the NE group (Fig. 4A). On the other hand, miR-133a expression showed increasing tendency in the E group, while it did not show significant change among the NE group (Fig. 4B). The difference in changing patterns of promoter methylation among the $\mathrm{E}$ and NE groups was analyzed by using generalized linear mixed 

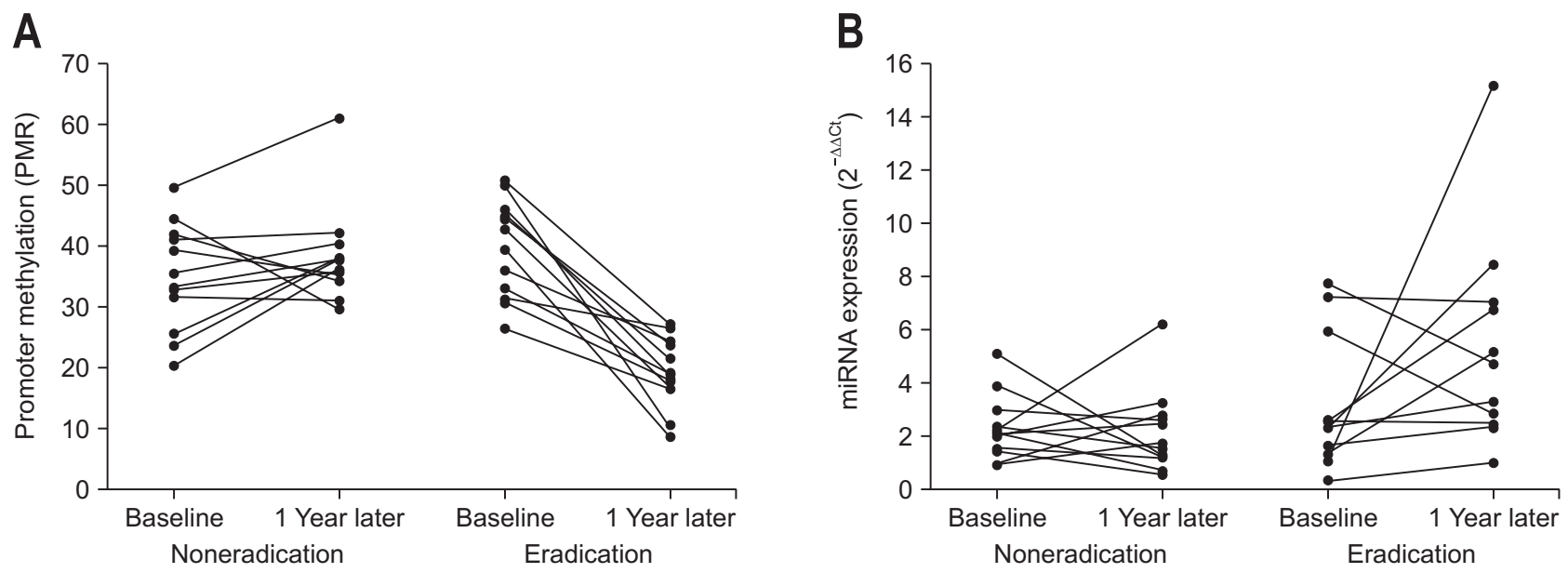

Fig. 4. Changes of promoter methylation levels (A) and expression levels (B) of miR-133a before and 1 year after Helicobacter pylori eradication therapy in normal mucosa of $H$. pylori positive gastric cancer patient. PMR, percentage of methylated reference.

model. Fixed effects were time and treatment assignment, while individual patients were taken as random effects. This analysis demonstrated an interaction between time and treatment with statistical significance $(\mathrm{p}<0.01)$. Likewise, the difference in changes of miR-133a expression according to the eradication was evaluated with the same model, where again the interaction between time and eradication showed statistical significance $(\mathrm{p}=0.03)$.

\section{DISCUSSION}

This study demonstrated that suppression of $m i R-133 a$ by its promoter methylation is associated with $H$. pylori-related gastritis and gastric cancer, and it could be reversed by $H$. pylori eradication. As far as we know, this is the first study to verify the reversibility of methylation-induced $m i R-133$ a downregulation caused by $H$. pylori infection through $H$. pylori eradication in relation to gastric carcinogenesis.

Although miR-133a was previously known as a muscle-specific miRNA, it was recently established to function as a tumor suppressor in various types of cancer, such as bladder cancer, ${ }^{23}$ head and neck cancer, ${ }^{24}$ lung squamous cell carcinoma, ${ }^{25}$ prostate cancer, ${ }^{26}$ colorectal cancer, ${ }^{27}$ non-small cell lung cancer, ${ }^{28}$ cervical cancer, ${ }^{29}$ pancreatic cancer, ${ }^{30}$ breast cancer, ${ }^{31}$ hepatocellular carcinoma, ${ }^{32}$ and gallbladder cancer. ${ }^{33}$ In addition, it has been revealed that miR-133a also plays tumor suppressive role in gastric cancer in several studies. ${ }^{14-17}$ Its downregulation in gastric cancer was also confirmed in The Cancer Genome Atlas dataset. ${ }^{16}$ So far, various target molecules of miR-133a have been suggested to be involved in gastric carcinogenesis and proliferation, such as transcription factor $\mathrm{Sp} 1,{ }^{14}$ insulin-like growth factor 1 receptor, ${ }^{15}$ antiapoptotic molecules, Mcl-1 and Bcl-xl, ${ }^{16}$ and ERBB2. ${ }^{17}$ However, the underlying mechanism of miR-133a downregulation has not been well discovered yet. In a previous study, miR-133a downregulation was found to be related with $H$. pylori infection in mice. ${ }^{13}$ Herein, we assumed that miR-133a would be regulated by promoter methylation induced by $H$. pylori infection. We have demonstrated that epigenetic modification, especially promoter methylation downregulates miR-133a by showing the decrease of methylation and increase of miR-133a expression by treatment with demethylating agent in gastric cancer cell culture. However, in a previous study, treatment with demethylating agent could not upregulate miR133a expression in gastric cancer cell line unlike histone methylation inhibitor and deacetylation inhibitor. ${ }^{16}$ Although the reason for this discrepancy is unclear, the different time interval before and after the treatment may have influenced. In the previous study, the intervals were 12 hours and 24 hours, whereas ours was 72 hours. Probably, sufficient recovery of miR-133a expression by demethylation may take longer than 24 hours. Similar to our results, there have been a study which revealed silencing of miR-133a by DNA methylation, although it was in colorectal cancer. ${ }^{34}$ Also another study have shown miR-133a downregulation by DNA methylation in relation to the development of cardiac hypertrophy induced by air-pollution. ${ }^{35}$ However, they showed methylation of only two $\mathrm{CpG}$ sites located at the transcription start site of $m i R-133 a$ rather than a CpG island located in the promoter site.

In current study, the promoter methylation showed consistent increase and the miR-133a expression showed consistent decrease according to the $H$. pylori-related disease severity: from $H$. pylori-negative control to $H$. pylori-gastritis, and then $H$. pyloripositive gastric cancer. This implies the possibility that the epigenetic silencing of miR-133a may be initiated by chronic $H$. pylori infection. As this study only examined $H$. pylori-infected gastric cancer patients, the methylation-silencing of miR-133a may not be involved in every gastric carcinogenesis. H. pyloriunrelated gastric carcinogenesis may be free from this mecha- 
nism. Also, most of the patients had intestinal type gastric cancer except for one diffuse type and one mixed type cancer in the noneradication group. Therefore we could not know if it would be the same in diffuse type gastric cancer. Nevertheless, in those with $H$. pylori infection, miR-133a downregulation may play important role in $H$. pylori-related intestinal type gastric cancer development.

Our study result also showed that the downregulation of miR-133a by $H$. pylori infection could be reversed by $H$. pylori eradication, which was also through the decrease of promoter methylation. This finding implies that some epigenetic modification involved in gastric carcinogenesis could be easily treated at certain time after once developed. Moreover, the gastric mucosal tissues used in this eradication experiment were normalappearing mucosa from those with gastric cancer. Considering the epigenetic field cancerization, ${ }^{36,37}$ this result suggests that the reversibility of miR-133a expression remains after gastric cancer development. As miR-133a downregulation is already proven to promote tumor proliferation and migration, ${ }^{14-17}$ treating the modification might be also effective in gastric cancer treatment, not only prevention.

Although there were age differences among the three groups, the different methylation and miR-133a expression levels were the same even after the age adjustment. Also, the small number of patients enrolled in this study is another limitation. Nonetheless, the fact that we showed statistical significance even with this small number further supports our results. Another limitation is that the comparison between cancer and noncancerous mucosa of cancer patients could not be made in this study because we did not perform paired sampling. This comparison should be made in further researches. Also the fact that this study did not evaluate the mechanism how $H$. pylori modulates methylation or how miR-133a regulates tumorigenesis is another limitation. It was over the scheme of this study. We believe this should be further studied in later researches to better understand this phenomenon.

In conclusion, downregulation of miR-133a caused by promoter methylation might be associated with $H$. pylori-related gastric carcinogenesis, and $H$. pylori eradication showed capacity to reverse its expression. Therefore, treating $H$. pylori infection even after gastric cancer development may have some portion of therapeutic role. Also this could be used as a biomarker for early diagnosis and a therapeutic target in gastric cancer. For such clinical use, further large scale studies are warranted.

\section{CONFLICTS OF INTEREST}

No potential conflict of interest relevant to this article was reported.

\section{ACKNOWLEDGEMENTS}

This study was supported by Research Resettlement Fund for the new faculty of Seoul National University, a grant number 0320130090 from the Seoul National University Hospital Research Fund and the Korean College of Helicobacter and Upper Gastrointestinal Research Foundation Grant.

Author contribution: J.H.L. and S.G.K., study conception and design, data analysis/interpretation; J.H.L., manuscript drafting; J.M.C., H.J.Y., J.S.K., and H.C.J., critical revision of manuscript; all authors read and approved the final manuscript.

\section{REFERENCES}

1. Ambros V. MicroRNAs: tiny regulators with great potential. Cell 2001;107:823-826.

2. Yamamichi N, Shimomura R, Inada K, et al. Locked nucleic acid in situ hybridization analysis of miR-21 expression during colorectal cancer development. Clin Cancer Res 2009;15:4009-4016.

3. Zhang Z, Li Z, Gao C, et al. miR-21 plays a pivotal role in gastric cancer pathogenesis and progression. Lab Invest 2008;88:13581366.

4. Liu T, Tang H, Lang Y, Liu M, Li X. MicroRNA-27a functions as an oncogene in gastric adenocarcinoma by targeting prohibitin. Cancer Lett 2009;273:233-242.

5. Nervi C, Fazi F, Grignani F. Oncoproteins, heterochromatin silencing and microRNAs: a new link for leukemogenesis. Epigenetics 2008;3:1-4.

6. Ando T, Yoshida T, Enomoto S, et al. DNA methylation of microRNA genes in gastric mucosae of gastric cancer patients: its possible involvement in the formation of epigenetic field defect. Int J Cancer 2009;124:2367-2374.

7. Suzuki H, Yamamoto E, Nojima M, et al. Methylation-associated silencing of microRNA-34b/c in gastric cancer and its involvement in an epigenetic field defect. Carcinogenesis 2010;31:20662073.

8. Hayashi Y, Tsujii M, Wang J, et al. CagA mediates epigenetic regulation to attenuate let-7 expression in Helicobacter pylori-related carcinogenesis. Gut 2013;62:1536-1546.

9. Toyota M, Suzuki H, Sasaki Y, et al. Epigenetic silencing of microRNA-34b/c and B-cell translocation gene 4 is associated with $\mathrm{CpG}$ island methylation in colorectal cancer. Cancer Res 2008;68:4123-4132.

10. Suzuki R, Yamamoto E, Nojima M, et al. Aberrant methylation of microRNA-34b/c is a predictive marker of metachronous gastric cancer risk. J Gastroenterol 2014;49:1135-1144.

11. Reinhart BJ, Slack FJ, Basson M, et al. The 21-nucleotide let-7 RNA regulates developmental timing in Caenorhabditis elegans. Nature 2000;403:901-906.

12. Esquela-Kerscher A, Slack FJ. Oncomirs: microRNAs with a role in cancer. Nat Rev Cancer 2006;6:259-269.

13. Saito Y, Suzuki H, Tsugawa H, et al. Dysfunctional gastric empty- 
ing with down-regulation of muscle-specific microRNAs in Helicobacter pylori-infected mice. Gastroenterology 2011;140:189198.

14. Qiu T, Zhou X, Wang J, et al. miR-145, miR-133a and miR-133b inhibit proliferation, migration, invasion and cell cycle progression via targeting transcription factor Sp1 in gastric cancer. FEBS Lett 2014;588:1168-1177.

15. Gong Y, Ren J, Liu K, Tang LM. Tumor suppressor role of miR133a in gastric cancer by repressing IGF1R. World J Gastroenterol 2015;21:2949-2958.

16. Liu Y, Zhang X, Zhang Y, et al. Identification of miRNomes in human stomach and gastric carcinoma reveals miR-133b/a-3p as therapeutic target for gastric cancer. Cancer Lett 2015;369:58-66.

17. Li C, Li X, Gao S, Li C, Ma L. MicroRNA-133a inhibits proliferation of gastric cancer cells by downregulating ERBB2 expression. Oncol Res 2017;25:1169-1176.

18. Dixon MF, Genta RM, Yardley JH, Correa P. Classification and grading of gastritis: the updated Sydney system. International Workshop on the Histopathology of Gastritis, Houston 1994. Am J Surg Pathol 1996;20:1161-1181.

19. Livak KJ, Schmittgen TD. Analysis of relative gene expression data using real-time quantitative PCR and the 2(-delta delta C(T)) Method. Methods 2001;25:402-408.

20. Park SY, Yoo EJ, Cho NY, Kim N, Kang GH. Comparison of CpG island hypermethylation and repetitive DNA hypomethylation in premalignant stages of gastric cancer, stratified for Helicobacter pylori infection. J Pathol 2009;219:410-416.

21. Eads CA, Danenberg KD, Kawakami K, et al. MethyLight: a highthroughput assay to measure DNA methylation. Nucleic Acids Res 2000;28:E32.

22. Ogino S, Kawasaki T, Brahmandam M, et al. Precision and performance characteristics of bisulfite conversion and real-time PCR (MethyLight) for quantitative DNA methylation analysis. J Mol Diagn 2006;8:209-217.

23. Chiyomaru T, Enokida H, Tatarano S, et al. miR-145 and miR133a function as tumour suppressors and directly regulate FSCN1 expression in bladder cancer. Br J Cancer 2010;102:883-891.

24. Kinoshita T, Nohata N, Fuse M, et al. Tumor suppressive microRNA-133a regulates novel targets: moesin contributes to cancer cell proliferation and invasion in head and neck squamous cell carci- noma. Biochem Biophys Res Commun 2012;418:378-383.

25. Moriya Y, Nohata N, Kinoshita T, et al. Tumor suppressive microRNA-133a regulates novel molecular networks in lung squamous cell carcinoma. J Hum Genet 2012;57:38-45.

26. Kojima S, Chiyomaru T, Kawakami K, et al. Tumour suppressors miR-1 and miR-133a target the oncogenic function of purine nucleoside phosphorylase (PNP) in prostate cancer. Br J Cancer 2012;106:405-413.

27. Dong Y, Zhao J, Wu CW, et al. Tumor suppressor functions of miR-133a in colorectal cancer. Mol Cancer Res 2013;11:10511060.

28. Wang LK, Hsiao TH, Hong TM, et al. MicroRNA-133a suppresses multiple oncogenic membrane receptors and cell invasion in nonsmall cell lung carcinoma. PLoS One 2014;9:e96765.

29. Song X, Shi B, Huang K, Zhang W. miR-133a inhibits cervical cancer growth by targeting EGFR. Oncol Rep 2015;34:1573-1580.

30. Qin Y, Dang X, Li W, Ma Q. miR-133a functions as a tumor suppressor and directly targets FSCN1 in pancreatic cancer. Oncol Res 2013;21:353-363.

31. Cui W, Zhang S, Shan C, Zhou L, Zhou Z. MicroRNA-133a regulates the cell cycle and proliferation of breast cancer cells by targeting epidermal growth factor receptor through the EGFR/Akt signaling pathway. FEBS J 2013;280:3962-3974.

32. Zhang W, Liu K, Liu S, Ji B, Wang Y, Liu Y. MicroRNA-133a functions as a tumor suppressor by targeting IGF-1R in hepatocellular carcinoma. Tumour Biol 2015;36:9779-9788.

33. Huang Y, Wu Y, Dong J, Han D, Yang S, Jiang L. MicroRNA-133a-3p exerts inhibitory effects on gallbladder carcinoma via targeting RBPJ. Am J Cancer Res 2016;6:2448-2462.

34. Chen WS, Leung CM, Pan HW, et al. Silencing of miR-1-1 and miR-133a-2 cluster expression by DNA hypermethylation in colorectal cancer. Oncol Rep 2012;28:1069-1076.

35. Huang L, Xi Z, Wang C, et al. Phenanthrene exposure induces cardiac hypertrophy via reducing miR-133a expression by DNA methylation. Sci Rep 2016;6:20105.

36. Ramachandran K, Singal R. DNA methylation and field cancerization. Epigenomics 2012;4:243-245.

37. Ushijima T. Epigenetic field for cancerization: its cause and clinical implications. BMC Proc 2013;7 Suppl 2:K22. 